\title{
Estimating Residual Service Life of Deteriorated Reinforced Concrete Structures
}

\author{
Sanjeev Kumar Verma ${ }^{1, *}$, Sudhir Singh Bhadauria ${ }^{2}$, Saleem Akhtar ${ }^{1}$ \\ ${ }^{1}$ Civil Engineering Department, Univ. Institute of Technology, Rajiv Gandhi Technological Univ., Bhopal, Madhya Pradesh, India \\ ${ }^{2}$ Director, S.G.S. Institute of Technology and Science, Indore, Madhya Pradesh, India \\ *Corresponding author: sanjeev.apm@gmail.com
}

Received May 03, 2013; Revised June 15, 2013; Accepted June 18, 2013

\begin{abstract}
Evaluating present condition of reinforced concrete (RC) structures is necessary for planning future maintenance and estimating residual service life of structures. A ten point (0-9) condition rating system is proposed for obtaining present condition of RC structures based on the measured values of concrete cover, carbonation depth and chloride concentration at rebar depth through in-situ tests. Proposed condition rating has been related to maintenance, inspection and replacement priorities. A model similar to Tutti’s model (1982) (Figure 1) has been developed and presented in this article to predict remaining service life of deteriorated structure, by evaluating present condition of RC structures.
\end{abstract}

Keywords: concrete, service life, chlorination, carbonation, deterioration

\section{Introduction}

Cement concrete is one of the most widely used materials for construction of structures, and concrete structures have been considered to be durable with large life. Inappropriate designs and construction processes can cause early deterioration of structures, so continuous monitoring of field structures is required to evaluate the condition of structures, but many times it is not possible to monitor structures continuously. Therefore, models are required to estimate residual service life of structures on the basis of present condition. For this improvement in the understanding of deterioration processes and their effect on the residual load bearing capacity of structures has been required (Wang and Liu 2010) [1].

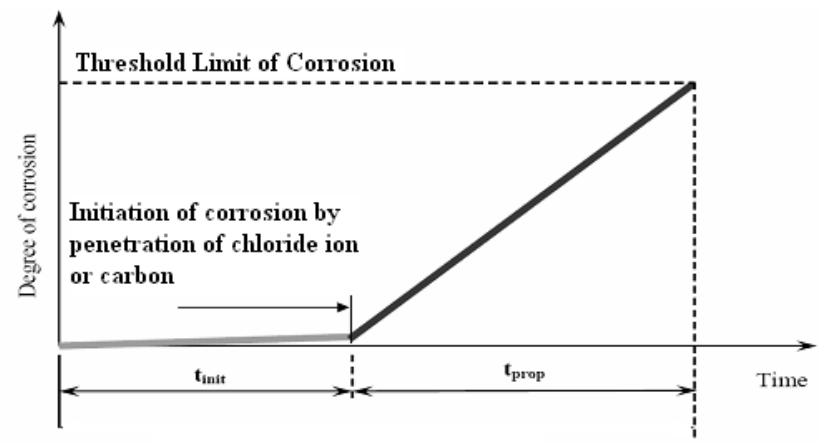

Figure 1. Service life model by Tutti (1982)

Service life of RC structures has been divided into different phases by researchers and engineers. Many researchers considered Tutti's (1982) [2] model for predicting deterioration, and they divided service life of RC structures in two phases. First is initiation, which is the time required for carbon dioxide or chloride ion to penetrate to the rebar level and initiate corrosion, and second is propagation which is the time between initiation and cracking, and many researchers adopted this model. Present article proposed a method for estimating residual service life of RC structures based on present condition evaluated by a proposed condition rating system. And in the last in conclusion and discussion section a table is presented showing all the parameters required to estimate the residual service life of RC structures.

\section{Description of Model}

A model has been developed and presented in this article to predict the residual service life of RC structures, by evaluating present condition of structures from a proposed condition rating system presented in this paper.

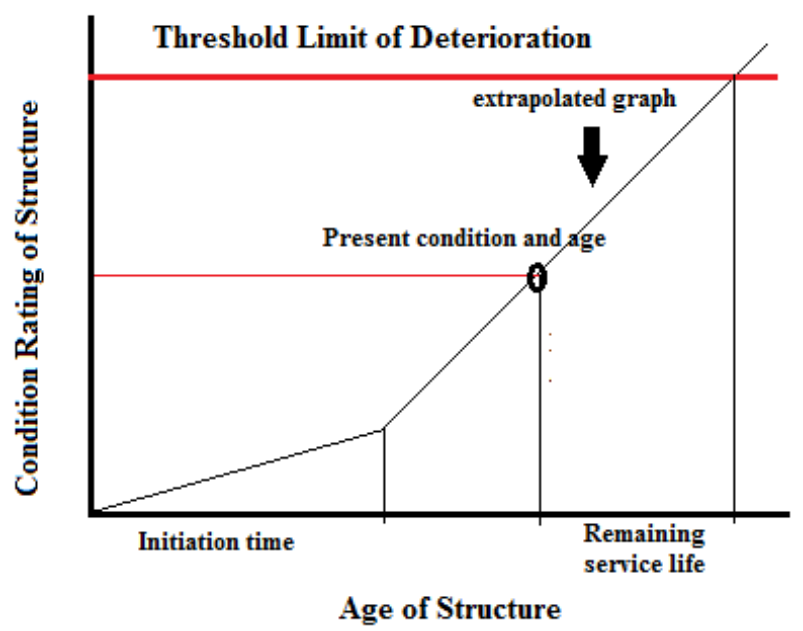

Figure 2. model for predicting remaining service life 
In the present model service life of RC structures is divided into two parts initiation and propagation, similar to Tutti's model, as shown in Figure 2. Initiation time means time required to initiate the corrosion either when carbonation depth becomes equal to concrete cover or when chloride concentration of the concrete reaches to its threshold value. Propagation time is period between initiation and failure of structures. Also a ten point (0 to 9) condition rating system has been presented here based on chloride content and carbonation depth, similar to condition rating system proposed by Mitra et al. (2010)[3] with some minor changes.

\section{Brief Literature Review}

Degradation of concrete structures means gradual decrease in performance, degradation process in concrete mainly takes place due carbonation and chloride ingress causing corrosion. Several researchers estimated residual service life of structures based on carbonation and chlorination process by dividing service life in different phases. Pan and Wang (2011) [4] evaluated the service life of RC Structures in three Key steps, namely chemical ingress, steel corrosion and concrete cracking. A model to determine residual stiffness of cracked concrete has been developed by Li and Yang (2011) [5]. Balafas and Buroyne (2011) [6] stated that corrosion controls the lifetime of a bridge, which has two periods 1) chloride penetrates to the bar depth until the bar starts to corrode, 2) rust with higher volume is produced and puts pressure on the cover, which leads to cover spalling, also developed a model to determine the time span of two periods.

Wang and Liu (2010) [1] presented a simplified methodology capable of estimating residual life of corroded RC beams, this method used damaged material properties, and accounts for the length of partial corrosion and the amounts of corrosion. Proposal based on the electrical resistivity has been made by Andrade and Andrea (2010) [7] to calculate both the initiation and propagation periods, as well as for predicting concrete aging related to durability. Okasha and Frangopol in (2010) [8]presented computational methodology for the life cycle prediction and service life estimation of bridges using advanced modeling tools, this methodology employed incremental nonlinear FEA. Agarwal et al.(2010) [9] described a 7 scale condition rating used to calculate the deterioration rates for each bridge element. Bridge condition rating scale ranges from 7 to 1,7 being new and 1 being failed condition. Mitra et al. (2010) [3] developed method for obtaining condition index of corrosion distressed RC building using in-situ investigations for carbonation and chloride content.

Cheung et al. (2009) [10] developed a 2-D FE coupled model to evaluate the chloride penetration process in varying environment to predict the corrosion initiation time. Liang et al. (2009) [11] proposed a mathematical model based on Fick's $2^{\text {nd }}$ law of diffusion and other previous models to study the service life of RC bridges. The corrosion process has three stages, the initiation time (tc), the depassivation time (tp), and the corrosion (propagation) time (tcorr). The total service life of pier for the existing RC bridge can be expressed as $t=t c+t p+$ tcorr. Bastidas-Arteaga et al. (2009) [12] developed a model in which corrosion-fatigue deterioration process has been divided into three stages: (1) corrosion initiation and pit nucleation, (2) pit-to-crack transition and (3) crack growth. According to Conciatori et al. (2009) [13] initiation period of chloride induced steel reinforcement corrosion in reinforced concrete is the time it takes for chloride ions to penetrate from the concrete surface and migrate into the cover concrete. The corrosion of concrete structures can be described as a two-stage process by Zhang and Lounis (2009) [14] as corrosion initiation and propagation stage.

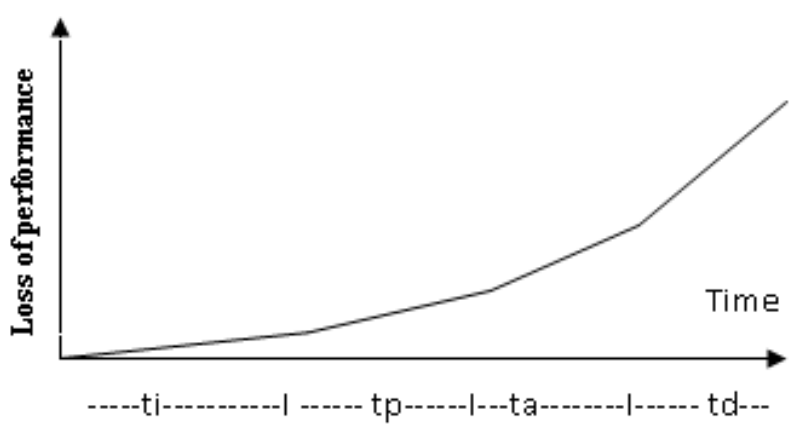

Figure 3. phases of service life as described by Song et al. (2007)

Bastidas-Arteaga et al. (2008) [15] divided Structural life-cycle in 3 stages time to corrosion initiation, time to crack initiation and severe cracking, and when crack width reaches threshold value. Song et al. in (2007) [16] used micromechanics based corrosion model to predict the service life of RC structures and divided service life in four parts (Figure 3) initiation period (ti), propagation period (tp), acceleration period (ta), and deterioration period (td).

Masada et al. (2007) [17] proposed a risk assessment method to compute overall structural health rating based on new high resolution (0-9) rating. Vu and Stewart (2005) [18] described excessive cracking in two stages as shown in Figure 4, (1) Crack initiation which is time before first cracking (hairline crack of $0.05 \mathrm{~mm}$ width). (2) Crack propagation which is time required by crack to develop from first cracking to a limit crack width.

Deterioration of concrete element due to reinforcement corrosion have been divided into two phases initiation and propagation by Roelfstra et al. (2004) [19], initiation phase starts with the construction and ends with the depassivation of the reinforcing steel. Propagation phase begins with the depassivation of the reinforcing steel and ends with the structural failure or complete dissolution of reinforcing steel. Beek et al. (2003) [20] distributed service life into two parts (i) Initiation period: during this lifetime extending measures are fully effective. (ii) Propagation period: during this lifetime extending measures loses its effectiveness. Liang (2002) [21] categorized evaluated bridges in grades I, II, III, IV, and V, which are described as non damage, light damage, moderate damage, severe damage, and unfit for service, respectively. $\mathrm{Li}$ et al. (1999) [22] presented a comprehensive experimental program aiming to investigate strength and serviceability deterioration of concrete structures, based on following (1) half cell potential (2) depth of chloride penetration and (3) chloride concentration. Somerville (1994) [23] represented the process of deterioration, reduction in strength and service 
life of an existing structure during its in-service performance by simplified sketch shown in Figure 5. The residual life of a structure at current time is a function of many complex parameters. Three key parameters influencing and controlling residual life of concrete structures are - Present performance, Rate of deterioration, Minimum Acceptable performance.

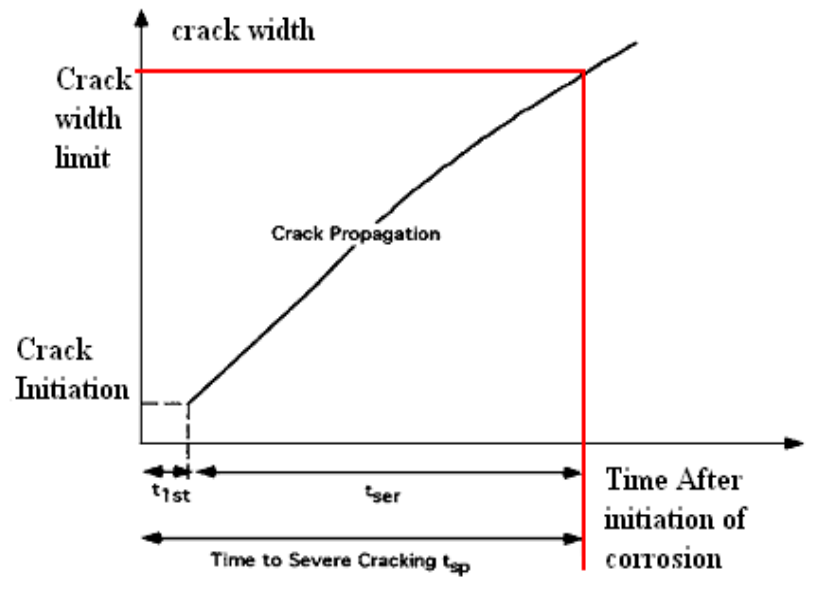

Figure 4. Crack initiation and propagation by Vu and Stewart (2005)

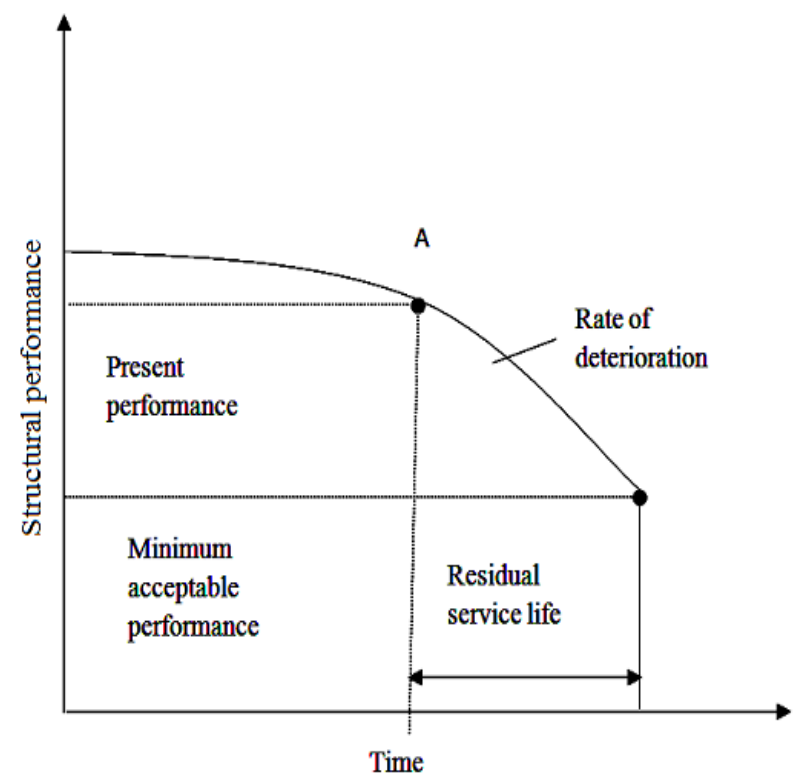

Figure 5. Deterioration of Structural Performance (Somerville 1994)

\section{Condition Rating System and Estimation of Residual Service Life}

Corrosion initiation period can be defined as time required for carbonation front to reach the rebar level depth i.e. carbonation depth becomes equal to the concrete cover, or when chloride concentration of the concrete surrounding the rebar reaches to its threshold value $(0.2 \%$ by the weight of concrete).

Usually carbonation models relates carbonation depth with the age of structures, mostly carbonation models are based on Fick's first law of diffusion

$$
C d=K \cdot t^{1 / 2}
$$

where $\mathrm{Cd}$ is carbonation depth, $\mathrm{t}$ is age of the structure and $\mathrm{K}$ is the coefficient of carbonation, several authors proposed value of ' $K$ ' based on concrete quality, aggregate types, exposure conditions, and moisture content. By selecting best suitable value of ' $K$ ' from the several proposed values or by evaluating value of ' $K$ ' by performing curve fitting of experimental data, corrosion initiation time can be evaluated by following equation.

$$
t=\sqrt{(C d / K)}
$$

Chloride concentration above threshold value initiates corrosion process, chloride induced corrosion process are mainly modeled using Fick's second law of diffusion presented in Equation. (3)

$$
\frac{\partial c}{\partial t}=\frac{\partial}{\partial x}\left[D \cdot \frac{\partial c}{\partial x}\right]
$$

where ' $C$ ' is the chloride content at depth ' $x$ ' and time ' $t$ ', ' $\mathrm{D}$ ' is the diffusion coefficient, corrosion initiation time which is the time required by chloride content at rebar depth to reach threshold value, can be evaluated using well known solution of above law

$$
\mathrm{t}_{\text {init }}=\frac{c^{2}}{4 D}\left[\operatorname{erf}^{-1}\left(1-\frac{c t h}{c s}\right)\right]^{-2}
$$

where $c=$ concrete cover, $\mathrm{Cs}=$ surface chloride content, $\mathrm{Cth}=$ threshold chloride content and erf is the well known error function

$$
\operatorname{erf}(u)=\frac{2}{\sqrt{\pi}} \int_{0}^{u} e^{-t^{2}} d t
$$

Following variable are required to calculate initiation period and estimating residual service life of RC structure.

$\mathbf{c r}=$ condition rating of structures ( 0 to 9 ) as given in Table 1 .

$\mathbf{c c}=$ concrete cover $(\mathrm{mm})$.

$\mathbf{c d}=$ carbonation depth evaluated $(\mathrm{mm})$.

dccd = Difference between concrete cover and carbonation depth $(\mathrm{mm})=\mathbf{c c}-\mathbf{c d}$.

cl $=$ Chloride concentration (\% wt. of concrete).

tcd= time period for carbonation to reach rebar depth after construction, from Equation (2)

tcl= time required for chloride content to reach the threshold value (0.2\%) at rebar level, from Equation (4).

Carbonation depth and chloride content can be modeled with respect to time, by using Fick's laws of diffusion, by applying any other diffusion principle or by applying curve fitting to the experimental data for developing relationship between these parameters and age of the structures. Time periods $\boldsymbol{t} \boldsymbol{c d}$ and $\boldsymbol{t} \boldsymbol{c l}$ can be calculated by using Equation (2) and Equation (4), and initiation period is the smaller value among tcd and $\boldsymbol{t} \boldsymbol{c l}$. After evaluating initiation period and obtaining cr from Table 1, plot a graph between condition rating and age of the structure using initiation time and current condition rating of the structure as shown in Figure 2. Now extrapolate the graph to evaluate time between present condition rating and any other condition rating. The above procedure is presented in the following flow chart (Figure 6). 
Table 1. Ten point Condition Rating system for RC structures

\begin{tabular}{|c|c|c|c|}
\hline $\begin{array}{l}\text { Condition Rating } \\
\text { (CR) }\end{array}$ & Failure Extent & $\begin{array}{c}\text { Description } \\
\text { (In terms of cl and dccd) }\end{array}$ & Action required \\
\hline 0 & safe & $\mathrm{cl}<0.2$ and dccd $>0$ and age $\leq 10$ & Excellent condition \\
\hline 1 & good & $\mathrm{cl}<0.2$ and dccd $>0$ and age $>10$ & No maintenance required \\
\hline 2 & $\begin{array}{l}\text { Low risk but } \\
\text { satisfactorily }\end{array}$ & $\begin{array}{c}\mathrm{cl}<0.2 \text { and } \mathrm{dccd} \leq 0 \\
\text { or } \\
\mathrm{cl}=0.2 \text { and } \operatorname{decd} \geq 0\end{array}$ & $\begin{array}{c}\text { Corrosion initiated, required regular } \\
\text { inspection }\end{array}$ \\
\hline 3 & fair & $0.25>\mathrm{cl}>0.2$ and $\mathrm{dccd}>0$ & Required frequent inspections \\
\hline 4 & Moderate risk & $0.25>\mathrm{cl}>0.2$ and $\mathrm{dccd} \leq 0$ & $\begin{array}{l}\text { No immediate maintenance, it may be } \\
\text { delayed }\end{array}$ \\
\hline 5 & poor & $0.3>\mathrm{cl} \geq 0.25$ and $\mathrm{dccd}>0$ & $\begin{array}{l}\text { Maintenance is required to increase the } \\
\text { service life }\end{array}$ \\
\hline 6 & High risk & $0.3>\mathrm{cl} \geq 0.25$ and $\mathrm{dccd} \leq 0$ & $\begin{array}{c}\text { Maintenance is must for continuous } \\
\text { use, likely to repair }\end{array}$ \\
\hline 7 & serious & $0.4>\mathrm{cl} \geq 0.3$ and $\mathrm{dccd}>0$ & $\begin{array}{c}\text { Structure must be closed for } \\
\text { maintenance }\end{array}$ \\
\hline 8 & critical & $0.4>\mathrm{cl} \geq 0.3$ and $\mathrm{dccd} \leq 0$ & Poor condition not likely to be repaired \\
\hline 9 & failure & $\mathrm{cl} \geq 0.4$ & Replacement of structures \\
\hline
\end{tabular}

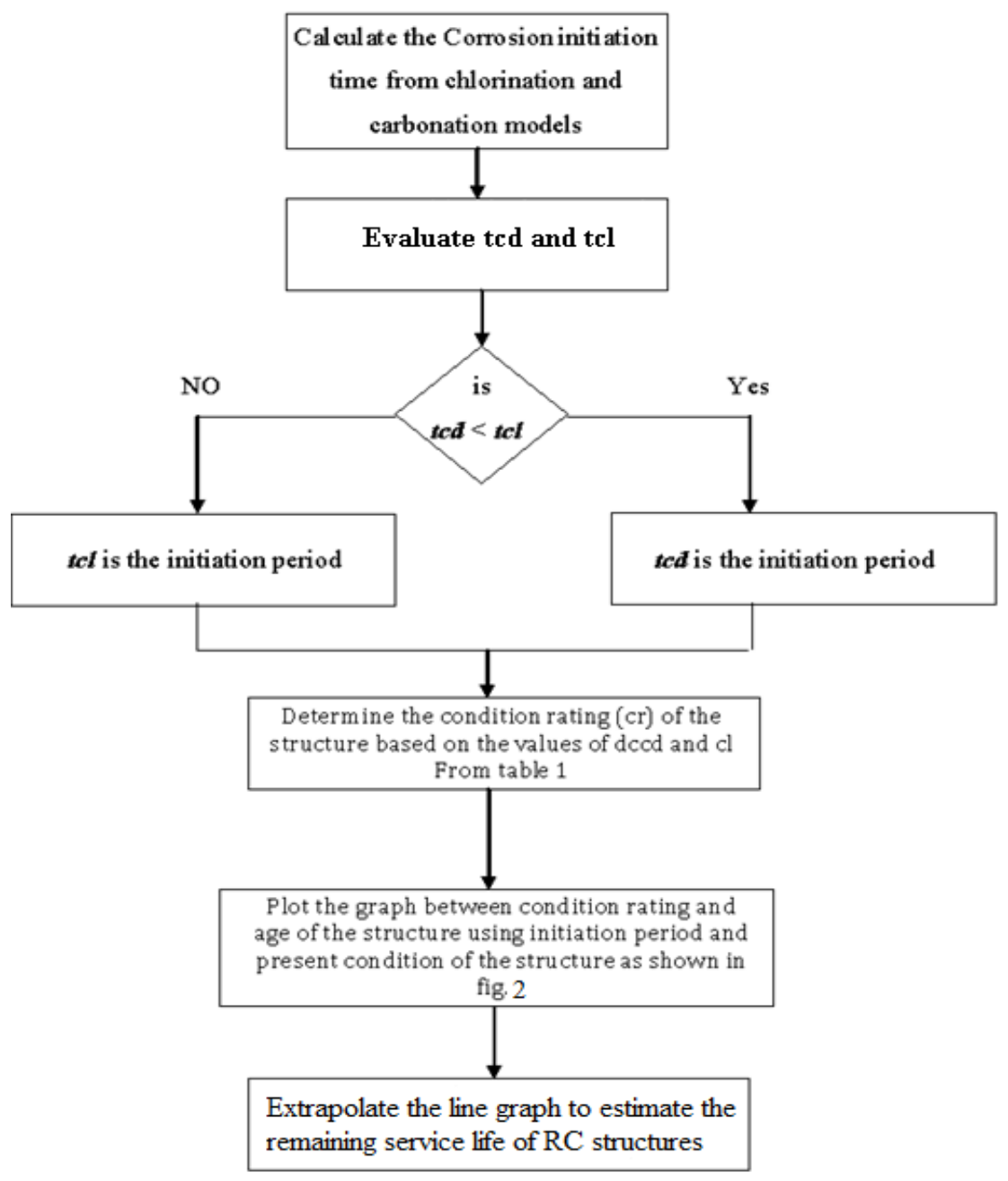

Figure 6. flow chart for estimating residual service life of structures

\section{Conclusion and Discussion}

A method to estimate residual service life of deteriorated RC structures based on the current condition has been presented in this article. Present condition of structures can be evaluated based on measured values of chloride content at rebar depth, carbonation depth, and concrete covers with a proposed condition rating system presented in Table 1, of the article. Corrosion initiation time can be evaluated using Equation (2) and Equation (4).

From Figure 3, Figure 4 and Figure 5 it has been observed that performance of RC structures deteriorated with increase in age of the structures. In Figure 3 presented by song et al. (2007) [16] the slope of performance curve has been increasing with the age of structures, and in last phase degradation of RC structures increases rapidly and finally resulting in failure of structures. Vu and Stewart (2005) [18] also presented in Figure 4 that crack propagation increases rapidly once 
cracks have been initiated due to corrosion. In Figure 5 a performance deterioration curve is presented by Somerville in 1994 [23] and it has been observed that deterioration increases with the age of structures and residual service life is the time between present age and age required to reach minimum acceptable performance. Following parameters shown in Table 2 have been selected to be considered while performing estimation of service life by the proposed method.

Table 2. Parameters required for estimating residual service life of RC structures

\begin{tabular}{|c|c|c|}
\hline S No. & Parameter & Utility \\
\hline 1 & Age of the structure & $\begin{array}{l}\text { To evaluate residual } \\
\text { service life }\end{array}$ \\
\hline 2 & Concrete cover & \multirow{3}{*}{$\begin{array}{l}\text { To evaluate present } \\
\text { condition from condition } \\
\text { rating system }\end{array}$} \\
\hline 3 & Carbonation depth & \\
\hline 4 & $\begin{array}{l}\text { Chloride content at Rebar } \\
\text { depth }\end{array}$ & \\
\hline 5 & concrete quality & \multirow{4}{*}{$\begin{array}{l}\text { To obtain coefficient of } \\
\text { carbonation 'K' from } \\
\text { values proposed by } \\
\text { several authors }\end{array}$} \\
\hline 6 & Types of aggregate & \\
\hline 7 & Exposure conditions & \\
\hline 8 & Moisture content & \\
\hline 9 & Surface chloride content & \multirow{3}{*}{ Chloride ingress model } \\
\hline 10 & Threshold chloride content & \\
\hline 11 & Chloride diffusion coefficient & \\
\hline
\end{tabular}

This method can be used by engineers to evaluate remaining service life of RC structures or time before any other condition level of structures, for planning maintenance and replacement of structures.

\section{Refrences}

[1] Wang, X., and Liu, X., "Simlified methodology for the evaluation of the residual strength of corroded reinforced concrete beams”. J. Perf. Constr. Fac., 24(2), 108-119. 2010.

[2] Tutti, K., “Corrosion of steel in concrete”. Swed. Cem. Conc. Res. Ins., 17-21. 1982.

[3] Mitra, G., Jain, K.K., and Bhattacharjee, B., "Condition assessment of corrosion-distressed reinforced concrete buildings using Fuzzy logic”. J. Perf. Constr. Fac., 24(6), 562-570. 2010.

[4] Pan, T., and Wang, L.,"Finite - element analysis of chemical transport and reinforcement corrosion-induced cracking in variably saturated heterogeneous concrete”. J. Eng. Mech., 137(5), 334-345. 2011.

[5] Li, C.Q., and Yang, S.T., "Prediction of concrete crack width under combined reinforcement corrosion and applied load”. J. Eng. Mech., 137(11), 722-731. 2011.

[6] Balafas, I., and Burgoyne, C.J.,"Modeling the structural effects of rust in concrete cover”. J. Eng. Mech., 137(3), 175-185. 2011.

[7] Andrade, C., and Andrea, R.,"Electrical resistivity as microstructural parameter for the modeling of service life of reinforced concrete structures”. $2^{\text {nd }}$ Int. Sym. on Ser. Life Des. Inf. , 4-6 Oct., Delft, Netherlands, 379-388. 2010.
[8] Okasha, N.M., and Frangopol, D.M.,"Advanced modeling for efficient computation of life cycle performance prediction and service life estimation of bridges”. J. Comp. Civil Eng., 24(6), 548-556. 2010.

[9] Agrawal, A.K., Kawaguchi, A., and Chen, Z., "Deterioration rates of typical bridge elements in new York”. J. Brid. Eng., 15(4), 419429. 2010.

[10] Cheung, M.M.S., Zhao, J., and Chan, Y.B.,"Service life prediction of RC bridge structures exposed to chloride environments”. J. Brid. Eng., 14(3), 164-178. 2009.

[11] Liang, M., Huang, R., Feng, S., and Yeh, C., "Service life prediction of pier for the existing reinforced concrete bridges in chloride-laden environment”. J. Mar. Sci. Tech., 17(4), 312-319. 2009.

[12] Bastidas-Arteaga, E., Bressolette, P., Chateauneuf, A., and Sanchez-silva, M.,"Probabilistic lifetime assessment of structures under coupled corrosion-fatigue deterioration processes”. Struc. Saf., 31, 84-96. 2009.

[13] Conciatori, D., Laferriere, F. and Bruhwiler, E., "Comprehensive modeling of chloride ion and water ingress into concrete considering thermal and carbonation state for real time”. Cem. Con. Res., 40, 109-118. 2009.

[14] Zhang, J.Y., and Lounis, Z., "Nonlinear relationship between parameters of simplified diffusion-based model for service life design of concrete structures exposed to chlorides”. Cem. and Con. Comp. , 31(8), 591-600. 2009.

[15] Bastidas-Arteaga, Sanchez-silva, M., Chateauneuf, A., and Silva, M.R., “Coupled reliability model of biodeterioration, chloride ingress and cracking for reinforced concrete structures”. Struc. Saf., 30, 110-129. 2008.

[16] Song, H., Kim, H., saraswathy, V., and Kim, T. "A micromechanics based corrosion model for predicting the service life of reinforced concrete structures". Int. J. Electrochemical Sci., 2, 341-354. 2007.

[17] Masada, T., Sargand, S.M., Tarawneh, B., Mitchell, G.F., and Gruver, D., "Inspection and risk assessment of concrete culverts under Ohio’s bridge”. J. Perf. Constr. Fac., 21(3), 225-233. 2007

[18] Vu, K.A.T., Stewart, M.G., "Predicting the likelihood and extent of reinforced concrete corrosion- induced cracking”. J. Struc. Eng.131 (11), 1681-1689. 2005.

[19] Roelfstra, G., Hajdin, R., Adey, B., and Bruhwiler, E., "Condition evolution in bridge management systems and corrosion - induced deterioration”. J. Brid. Eng., 9(3), 268-277. 2004.

[20] Beek, A.V., Gaal, G.C.M., Noortwijk, J.M.v, and Bakker, J.D., "Validation model for service life prediction of concrete structures”. $2^{\text {nd }}$ Int. Rilem w/s on Life Pred. Ag. Mang., 5-6 May, Peris, France, 275- 267. 2003.

[21] Liang, M., Lin, L., and Liang, C., "Service life prediction of existing reinforced concrete bridges exposed to chloride environment”. J. Infra. Sys., 8(3), 76-85. 2002.

[22] Li, C.Q., Cleven, M., and Isaac, F., "Steel corrosion in concrete: A comprehensive experimental program and preiliminary results”. Dur. Build. Mat. Comp., 8, 331-340.1999.

[23] Somerville, G.,"The interdependence of research, durability and structural design of concrete"; Proceeding of symposium on durability and design life of Structure; Institution of Civil Engineers, 26/27 November, Thomas Telford, London.1994. 